\title{
Fertilizer 'solution' could turn local problem global
}

\section{Protecting soil and water from pollution may mean releasing more greenhouse gas.}

Sir - It was gratifying to see the range of well-argued responses in Correspondence (Nature 427, 99; 2004) to your News Feature "Fertilized to death" (Nature 425, 894-895; 2003). All the correspondents put forward valid points regarding the pros and cons of nitrogen fertilizer use. However, a key issue was overlooked, that of 'pollution swapping'.

Pollution of our ground and surface waters by nitrogen fertilizers poses a host of potential environmental problems, including toxic algal blooms and fish kills. Preventing nitrogen fertilizer from leaching into drainage waters, as may be achieved by no-till practices, would therefore seem to be an obvious goal.

Here, though, we run into a real danger of what has become known as 'pollution swapping'. If the added nitrogen fertilizer is neither taken up by plants nor lost via leaching, then more of it is likely to end up as the powerful greenhouse gas nitrous oxide (A. Mosier et al. Nutr. Cyc. Agroecosyst. 52, 225-248; 1998), through the process of denitrification.

By limiting the pollution of water by nitrogen fertilizers, using so-called 'buffer strips' or strategies such as no-till farming, we may simply be swapping a relatively local pollution problem for the global problem of climate change (M. Hefting et al. J. Environ. Qual. 32, 1194-1203; 2003).

Which of these is the more important problem depends on your perspective, and there may be other land-use strategies through which we can limit nitrogen leaching without bumping up emissions of nitrous oxide.

In the end, though, the answer for much of the developed world is likely to be a familiar one - use less fertilizer, but more efficiently.

David S. Reay

School of Geosciences, Ecology and Resource Management, University of Edinburgh, Darwin Building, Mayfield Road, Edinburgh EH9 3JU, UK

\section{Framework reveals lack of basic-research funds}

Sir - Your recent Editorial "Science needs the commission, Sturm und Drang and all" (Nature 426, 481; 2003) is most welcome. Among other things, it makes a muchneeded and previously unrecognized point, namely that oversubscription by European scientists to funding offered by the European Commission's Framework programmes is "a sign of the need for European-level funding for basic research which does not exist elsewhere", not "a sign of [the programmes'] success", as naively argued by director general Achilleas Mitsos.

I would like to add a local observation. Swedish researchers have received more money through Framework programmes than the Swedish government has put into the programmes (see www.eufou.se). This is less a sign of Swedish scientists' excellence in application-writing than of an acute shortage of funding in national research councils and foundations. With an annual budget of $€ 44$ million (US\$55 million), the Swedish Medical Research Council, for example, would only be able to finance three of the Network of Excellence collaborations offered by the latest Framework programme. Carlos F. Ibanez

Division of Molecular Neurobiology, Department of Neuroscience, Karolinska Institute, Retzius väg 8, A2:2, 17177 Stockholm, Sweden

\section{Working hard for the money}

Sir - It is a pity that John A. Duley, in Correspondence ("Tough lessons for survival in hard academic times", Nature 427, 13; 2004), did not include Steven
Weinberg's fourth "golden lesson" (Nature 426, 389; 2003) in his own list - namely, to learn some of the history of science.

If you look back further than 25 years, it becomes clear that relatively low pay for research scientists has been a feature of the profession since its earliest days.

The junior scientists who sailed on the research vessel Challenger 130 years ago,

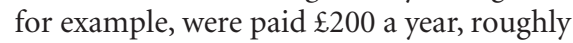
equivalent to $£ 7,000$ (US\$12,700) today (A. L. Rice, Arch. Nat. Hist. 16, 213-220; 1989), or less than $40 \%$ of the "poor salary" example given by Duley.

Albert Einstein did his most important science after hours while working at his 'real job' as a third-class patent clerk in the Bern patent office.

Gertrude Elion (who won the Nobel Prize in medicine in 1988) started working as an unpaid laboratory technician in the 1930 s and only after proving herself could enjoy the "magnificent" sum of \$20 a week.

Clearly if any of these and many other individuals had chosen their research paths "according to hard-headed economics", as Duley advises, we would all be the poorer. To borrow Donna Summer's immortal words, a merchant banker "works hard for the money, so you better treat her right" — job satisfaction is not guaranteed even when the pay is good.

My own laboratory website lists three basic requirements for joining the group: an open mind, an interest in science for its own sake and a tolerable sense of humour. Disregarding the third idiosyncratic requirement, I would argue that students who fit the first two criteria should follow Steven Weinberg's advice to the letter. Mike Fainzilber

Department of Biological Chemistry, Weizmann Institute of Science, 76100 Rehovot, Israel

\section{Pet breeding has a long and colourful history}

Sir — In his review of Tim Birkhead's entertaining book The Red Canary (Nature 425, 772; 2003), Jerry Coyne disputes the relevance of 'genetically engineering' red canaries (by crossing the birds with the South American red siskin and feeding them carotenoids) to the modern debate on transgenics. In my view, the current controversy surrounding the commercialization of GloFish, a fluorescent zebrafish with sea anemone genes (Nature 426, 372 and 596; 2003), could gain a useful perspective from the story of the red canary.

GloFish continues the historic tradition of genetic modification of pets that has resulted in such oddballs as peculiarly shaped dogs, hairless cats and coloured birds. The red canary is remarkable in that the red-factor gene was bred into the canary genome from a distinct species, and therefore does not differ in principle from GloFish. Members of the California Fish and Game commission, who voted against the sale of GloFish in the state and concluded that "aesthetic reasons are not sufficient justification for the genetic modification of animals", should probably endeavour to ban the sale of red canaries and other hybrid pets.

Sophien Kamoun

Department of Plant Pathology, The Ohio State University, Ohio Agricultural Research and Development Center, 1680 Madison Avenue, Wooster, Ohio 44691, USA

\section{correspondence}

Contributions to Correspondence may be submitted to corres@nature.com. They should be no longer than 500 words, and ideally shorter. Published contributions are edited. 